\title{
REFLEXÕES SOBRE O TRABALHO SOCIOEDUCATIVO NO ÂMBITO DA POLITICA DE ASSISTÊNCIA SOCIAL
}

\author{
Lindamar Alves Faermann \\ Universidade de Taubaté - UNITAU - Brasil
}

Dannúbia Aparecida Nascimento

Universidade de Taubaté - UNITAU - Brasil

\section{Resumo}

O presente artigo discute a importância do trabalho socioeducativo com famílias no âmbito da política de assistência social e as possíveis implicações desse trabalho no cotidiano dos sujeitos envolvidos, sobretudo no que toca às suas formas de pensar e de agir. Entende-se que as inovações trazidas pelo Sistema Único de Assistência Social (SUAS) apontam-no como referencial metodológico à intervenção dos profissionais. Nesse sentido, busca-se explicitar o trabalho socioeducativo como um dos caminhos para instigar processos emancipatórios junto às famílias e concretizar princípios que envolvem o SUAS, reconhecendo os avanços e os limites desse processo.

Palavras-chave: Trabalho socioeducativo. Política de Assistência Social. Serviço Social.

\section{Introdução}

Este artigo destaca a relevância do trabalho socioeducativo com famílias no âmbito da política de assistência social. Parte-se do pressuposto de que o trabalho socioeducativo se constitui em uma referência metodológica para concretizar alguns princípios que norteiam o SUAS, reconhecendo os avanços e os desafios colocados por essa política. Considera-se, portanto, o trabalho socioeducativo um instrumento técnico-operativo e, ao mesmo tempo, uma estratégia política a ser utilizada pelos profissionais para a organização e mobilização das famílias no campo das políticas públicas e para a ampliação de seus processos de consciência.

No contexto da política de assistência social, o trabalho com famílias compreende

Um conjunto de procedimentos efetuados a partir de pressupostos éticos,
conhecimento teórico-metodológico e técnico-operativo, com a finalidade de
contribuir para a convivência, reconhecimento de direitos e possibilidades de
intervenção na vida social de um conjunto de pessoas, unidas por laços
consanguíneos, afetivos e/ou de solidariedade, que se constitui em um espaço
privilegiado e insubstituível de proteção e socialização primárias, com o objetivo de
proteger seus direitos, apoiá-las no desempenho da sua função de proteção e
socialização de seus membros, bem como assegurar o convívio familiar e
comunitário, a partir do reconhecimento do papel do Estado na proteção e
socialização de seus membros mais vulneráveis. Tal objetivo materializa-se a partir
do desenvolvimento de ações de caráter "preventivo, protetivo e proativo",


reconhecendo as famílias e seus membros como sujeitos de direitos e tendo por foco as potencialidades e vulnerabilidades presentes no seu território de vivência (BRASIL-PAIF, 2012, p. 12,).

Nesse sentido, os marcos legais no Brasil indicam a construção de políticas que encarem a família como eixo básico de atuação, na medida em que é em seu interior que os indivíduos formam-se e onde se reproduzem suas condições de existência. Como instituição contraditória, tanto na sua dimensão interna (como grupo particular), quanto na externa, (como grupo coletivo), a família contém e expressa os antagonismos da sociedade. Dessa forma, é possível vislumbrar como as determinações sociais interferem na construção dos fenômenos que as envolve.

Tal abordagem requer análises que possibilitem desvelar a realidade das famílias em seu movimento e em suas contradições, sendo esse um ponto crucial quando se pensa em desenvolver ações com esse público.

A partir dessas considerações, apresenta-se neste artigo a concepção de famílias na perspectiva crítica, aportando reflexões no campo da política nacional de assistência social na perspectiva do SUAS. Em seguida, centra-se a discussão sobre o trabalho socioeducativo, evidenciando conceitos, princípios e desafios ao seu desenvolvimento.

\section{Famílias: problematizações sob o aporte da teoria crítica e concepções no campo da assistência social}

Tendo como suporte paradigmático a teoria crítica ${ }^{1}$ analisa-se a família como instituição social em permanente movimento. Portanto, longe de ser um bloco monolítico ou uma estrutura dada, a família sofre determinações econômicas, políticas e culturais da conjuntura e da história presente. Sendo assim, constrói-se permanentemente nas relações sociais, não sendo uma invenção eminentemente privada, mas essencialmente pública, tendo importante papel na estruturação da sociedade.

Como um produto histórico do sistema social, a família reflete o estado de cultura desse sistema, cumprindo uma função essencial na manutenção das relações burguesas, visto que a produção e a reprodução das condições da existência se realizam por meio do trabalho, da divisão social do trabalho, da procriação (nesse caso sexualidade e da instituição família) e do modo de apropriação da natureza. A esse respeito, lembra Marx (2009) que:

As determinadas fases de desenvolvimento da produção, do comércio e do consumo correspondem determinadas formas de constituição social, determinada organização

\footnotetext{
${ }^{1}$ Conjunto de elaborações teórico-analíticas formuladas pelas diversas correntes do marxismo, a partir da teoria social de Marx.
} 
da família, das ordens ou das classes; numa palavra, uma determinada sociedade civil. (MARX, 2009, p.225)

Analisar a família nessa perspectiva significa desnaturalizá-la, desvelando sua dinâmica e sua organização. Enquanto instituição histórica, a família constrói-se e reconstrói-se cotidianamente, através das relações que estabelece entre seus membros, vizinhança, comunidade, mercado e Estado. Assim, pode-se dizer que a família, longe de ser um "refúgio num mundo sem coração", vem cobrindo as insuficiências do Estado e das políticas públicas, sendo atravessada diretamente pela questão social (Campos, 2004).

Para a política de assistência social, "estamos diante de uma família quando encontramos um conjunto de pessoas que se acham unidas por laços consanguíneos, afetivos e, ou, de solidariedade" (BRASIL, 2004, p. 35). Tal concepção ultrapassa o modelo tradicional, visto ser esse limitado ao circuito biológico, exigindo problematizar sua realidade em meio à conjuntura econômico-social e às construções relacionais que a envolvem.

Conforme Mioto (2004, p. 135), a família não é um simples somatório de comportamentos, de anseios e de demandas individuais, mas um processo interativo de vidas e de trajetórias particulares e sociais de seus integrantes. Nesse sentido, a família pode ser definida "como um núcleo de pessoas que convivem em determinado lugar, durante um lapso de tempo mais ou menos longo e que se acham unidas, ou não, por laços sanguíneos". Para a autora, "estamos diante de uma família quando encontramos um espaço constituído de pessoas que se empenham umas com as outras, de modo contínuo, estável e não casual” (MIOTO, 1997, p.120).

Portanto, ao trazer a necessidade de se "considerar novas referências para a compreensão dos diferentes arranjos familiares, superando o reconhecimento de um modelo único baseado na família nuclear" (BRASIL, 2004, p. 29), a PNAS avança quanto ao reconhecimento, no âmbito da proteção, de famílias monoparentais, homoafetivas, homoparentais e famílias extensas, destacando que a intervenção no grupo familiar deve considerar "sua singularidade, sua vulnerabilidade no contexto social, além de seus recursos simbólicos e afetivos, bem como sua disponibilidade para se transformar e dar conta de suas atribuições (BRASIL, 2004, p. 29). Nesse sentido, pauta-se no "pressuposto de que para a família prevenir, proteger, promover e incluir seus membros é necessário, em primeiro lugar, garantir condições de sustentabilidade para tal” (BRASIL, 2004, p. 41).

Importa salientar que essas novas referências não devem ser compreendidas como fontes de desvios e de fragilidades, mas como expressões de novas sociabilidades presentes na sociedade atual. Para Mioto (2000, p.01), independentemente das formas que assume, a 
“família ainda é o espaço privilegiado na história da humanidade onde aprendemos a ser e a conviver".

Discutir as famílias, nessa perspectiva, implica analisar suas relações sob o viés da totalidade e por meio de consecutivas aproximações. Há que se dizer que a análise de totalidade "significa a percepção da realidade como um todo orgânico, estruturado, no qual não se pode entender um elemento, um aspecto, uma dimensão, sem perder sua relação com o conjunto" (LÖWY, 2003, p. 16).

Esse processo é fundamental para confrontar práticas que culpabilizam as famílias, visto que ainda prevalece a concepção de família idealizada e, por isso, são responsabilizadas quando um de seus membros apresenta problemáticas diversas.

\begin{abstract}
Embora haja o reconhecimento explícito sobre a importância da família na vida social e, portanto, merecedora da proteção do Estado, tal proteção tem sido cada vez mais discutida, na medida em que a realidade tem dado sinais cada vez mais evidentes de processos de penalização e desproteção das famílias brasileiras. Nesse contexto, a matricialidade sócio-familiar passa a ter papel de destaque no âmbito da Política Nacional de Assistência Social (BRASIL, 2004, p.35).
\end{abstract}

O reverso desse processo acentua estigmas e reproduz uma visão parcial que favorece a individualização dos fenômenos sociais e consequentemente das intervenções profissionais realizadas, contribuindo com discursos que penalizam as famílias. A naturalização e a individualização das expressões da questão social contribuem para a crescente penalização das famílias, particularizando situações que se inscrevem numa construção sócio-histórica.

A reificação que invade a vida social favorece essa apreensão, pois contribui para ocultar a essência desses processos que se mostram de modo aparente, como se fossem fenômenos naturais e absolutos. Ademais, a ideologia dominante sedimenta essa naturalização, em sua justificação da dinâmica capitalista.

Em face disso, manifestam-se nessa conjuntura, demandas de intervenções pontuais e fragmentadas junto às famílias, a exemplo de práticas terapêuticas, técnicas de mediação de conflitos e ações de responsabilidade individual. O contexto em que vivemos é propício aos apelos subjetivistas, a mecanismos de adaptação e de apaziguamento das relações. Trata-se de abordagens paliativas, que não vão à raiz dos fenômenos e que camuflam as desigualdades sociais existentes. Evidentemente que, para a razão instrumental, apta ao capital, não interessa revelar os seus fundamentos, mas gerenciar suas consequências.

Com isso, os profissionais que trabalham com famílias no âmbito das políticas públicas nem sempre reconhecem a incompatibilidade entre os direitos sociais e as normativas institucionais, resvalando em intervenções afetas às regras e aos argumentos da instituição, 
reiterando práticas que contribuem para a responsabilização e a criminalização das famílias. Igualmente corroboram com ações e discursos que, embora antigos, mostram-se com novas roupagens, a exemplo da meritocracia.

Desse modo, as relações familiares devem ser compreendidas como síntese de múltiplas determinações, isto é, como uma totalidade dinâmica e contraditória. Para Mioto (1997, p. 116), “esta compreensão se contrapõe ao entendimento de que a família é um grupo natural, limitado à essência biológica do homem e à sua continuidade através da consanguinidade e da filiação". Considerando-se, portanto, que estão inscritas nas relações mais amplas, as famílias evidenciam suas funções e seus significados para além do que é posto naturalmente.

\section{A Política Nacional de Assistência Social: reflexões sobre o Sistema Único da Assistência Social e o trabalho com famílias nesse campo}

A Constituição Federal de 1988 inscreveu a Seguridade Social como lócus de proteção social, composta pela saúde, previdência e assistência social. Dessa forma, somente em 1988 a assistência social ganha o estatuto de política pública não contributiva - direito do cidadão, dever do Estado. Por isso, para Yazbek (2008), a assistência social, começa seu percurso para o campo dos direitos, da universalização dos acessos e da responsabilidade estatal, a partir da Constituição Federal de 1988, com sua inclusão no campo da Seguridade Social.

Nesse contexto, a assistência social vem apresentando avanços expressivos, mediante mecanismos viabilizadores dos direitos sociais, destacando-se a aprovação em 2004 da Política Nacional de Assistência Social - PNAS e em 2005 do Sistema Único de Assistência Social - SUAS.

O SUAS, cujo modelo de gestão é descentralizado e participativo, estabelece a regulação e a organização dos serviços socioassistenciais em todo o território nacional. Esse novo modelo de gestão supõe um pacto federativo, com a definição de competências entre as esferas de poder (União, Estados e Municípios), sendo construído por meio de uma nova lógica de organização das ações, na qual os serviços, programas, projetos e benefícios são estruturados por níveis de complexidade, na área da proteção social básica e proteção social especial (média e alta complexidade), constituindo-se numa rede de serviços hierarquizada e tendo como referência o território (regiões e portes de municípios).

O SUAS normatiza os padrões de serviços, com vistas à qualidade no atendimento das famílias e a construção de indicadores sociais, tendo como funções a proteção básica e especial, a vigilância social e defesa dos direitos socioassistenciais. Assim, tem por escopo 
promover a segurança da acolhida, da renda, do convívio familiar e comunitário e da sobrevivência a riscos circunstanciais, por meio de serviços que busquem reverter as situações de vulnerabilidade social.

Há que se destacar que a vulnerabilidade social, que constitui e permeia a vida das famílias, decorre de processos político-econômicos responsáveis pela (re)produção das desigualdades sociais na sociedade capitalista, como a condição de subalternidade, de fragilidade e as dificuldades materiais e afetivas que vivenciam.

As análises totalizantes sobre as determinações da vulnerabilidade estão relacionadas ao aprofundamento da questão social resultante das contradições capital-trabalho, tendo por eixo as transformações societárias que, nas últimas décadas, afetaram o conjunto da vida social, notadamente o mundo do trabalho.

No âmbito da política nacional de assistência social, a vulnerabilidade particulariza a situação de indivíduos e de grupos fragilizados, jurídica ou politicamente, na promoção, proteção ou garantia de seus direitos sociais, abarcando sujeitos

\begin{abstract}
(...) com perda ou fragilidade de vínculos de afetividade, pertencimento e sociabilidade; ciclos de vida; identidades estigmatizadas em termos étnico, cultural e sexual; desvantagem pessoal resultante de deficiências; exclusão pela pobreza e, ou, no acesso às demais políticas públicas; uso de substâncias psicoativas; diferentes formas de violência advinda do núcleo familiar, grupos e indivíduos; inserção precária ou não inserção no mercado de trabalho formal e informal; estratégias e alternativas diferenciadas de sobrevivência que podem representar risco pessoal e social (BRASIL, 2004, p. 27).
\end{abstract}

Destaca-se que cabe ao SUAS produzir equidade no acesso aos bens e serviços por meio de uma rede de proteção que articule políticas, tendo as famílias como sujeitos centrais dessa proteção. Essa ênfase apoia-se na premissa de que para a família cuidar e proteger os seus membros é preciso que tenha a garantia de meios e de recursos para tal incumbência.

Portanto, em que pese suas tipologias e configurações, as famílias cumprem historicamente funções quanto ao cuidado e atenção de seus membros. Assim, pode-se dizer que a família constitui um dos grupos mais significativos na sociedade, na medida em que estabelece a mediação entre o sujeito e os costumes, as normas, a ética e as expectativas da classe a que pertence. Isso significa afirmar que esses elementos são sempre mediados pelas famílias face a face.

A família, independentemente dos formatos ou modelos que assume, é mediadora das relações entre os sujeitos e a coletividade, delimitando, continuamente os deslocamentos entre o público e o privado, bem como geradora de modalidades comunitárias de vida (BRASIL, 2004, p. 34-35). 
Compreender a família como núcleo em que as vulnerabilidades sociais são produzidas é central para que seja um espaço de resistência e proteção dessas situações. Ao pensar nas ações voltadas às necessidades das famílias, o SUAS considera que suas relações estão condicionadas às transformações sociais. Desse modo, prevê o impacto dessas transformações no seu interior, pois, na família, materializam-se os reflexos dos processos econômicos, políticos, culturais e sociais manifestos na pobreza, na miserabilidade e na exclusão.

\begin{abstract}
Essa postulação se orienta pelo reconhecimento da realidade que temos hoje através de estudos e análises das mais diferentes áreas e tendências. Pesquisas sobre população e condições de vida nos informam que as transformações ocorridas na sociedade contemporânea, relacionadas à ordem econômica, à organização do trabalho, à revolução na área da reprodução humana, à mudança de valores e à liberalização dos hábitos e dos costumes, bem como ao fortalecimento da lógica individualista em termos societários, redundaram em mudanças radicais na organização das famílias (BRASIL, 2004, p. 35).
\end{abstract}

Por conseguinte, o trabalho socioeducativo com as famílias pode ser de extrema importância. Como expressa Sposati (2004, p. 4), os serviços com as famílias devem ser norteados por princípios que favoreçam a conquista de sua autonomia, além de oferecerem condições de "resiliência/sustentabilidade, protagonismo, acesso a oportunidades, capacitações, acesso a serviços, a benefícios, a condições de convívio e socialização”.

Contudo, para que a política de assistência social torne-se efetiva para as famílias, são necessários investimentos técnicos e financeiros, além de proposição de ações integradoras que viabilizem o seu protagonismo e o acesso aos seus direitos sociais, pois, em que pesem os avanços no campo da assistência social, permanecem

(...) concepções e práticas assistencialistas, clientelistas, primeiro damistas e patrimonialistas. Décadas de clientelismo consolidaram neste país uma cultura tuteladora que não tem favorecido o protagonismo nem a emancipação dos usuários das Políticas Sociais e especialmente da Assistência Social aos mais pobres em nossa sociedade (YAZBEK, 2008, p.3).

\title{
Desafios e perspectivas: o trabalho socioeducativo com famílias no âmbito da política nacional de assistência social
}

O trabalho socioeducativo tanto pode ser entendido como um recurso a ser utilizado por profissionais de diferentes áreas e políticas em sua atuação com famílias, quanto compreende uma dimensão ontológica do trabalho dos profissionais cujas práticas apresentam funções sociais e educativas, visto que, em seu processo interventivo, movimentam essa dimensão, seja na perspectiva crítica ou na conservadora. 
Dessa forma, segundo Yazbek (2006, p.28), o trabalho socioeducativo pode assumir “características disciplinadoras, voltadas ao enquadramento do 'cliente' em sua inserção institucional e na vida social, como pode se voltar para uma perspectiva emancipadora, defendendo, preservando e efetivando direitos sociais"

Nesse sentido, “a ação educativa tem uma vertente político-ideológica: ou se pretende simplesmente manter tudo como está ou fazer um trabalho de contribuição para a transformação" (BARBOSA, 2013, p. 100). Essa afirmativa fundamenta-se no pensamento de Paulo Freire, segundo o qual, mesmo que não percebamos, nossa prática como trabalhadores sociais é para libertação ou dominação dos homens.

Nessa mesma direção, Abreu (2002) assinala que a perspectiva teórico-metodológica adotada pelo profissional e as funções desempenhadas em determinadas condições e relações podem conservar ou transformar a concepção de mundo dos sujeitos, promovendo determinadas maneiras de pensar e de agir.

No entanto, o trabalho socioeducativo com famílias na direção crítica anula a possibilidade de uma educação pautada em relações de poder e na transmissão de crenças e valores burgueses. Ao contrário, a partir de uma relação conjunta e horizontal entre os envolvidos, busca estimular processos reflexivos. Segundo Mioto (2009, p.503), o processo reflexivo, característico das ações socioeducativas, desenvolve-se no percurso que o profissional faz com as famílias para buscar respostas às suas necessidades. Desse modo, pauta-se no "princípio de que as demandas que chegam às instituições, trazidas por indivíduo, grupos ou famílias são reveladoras de processos de sujeição à exploração, de desigualdades nas suas mais variadas expressões ou de toda sorte de iniquidades sociais".

Portanto, o trabalho socioeducativo com famílias implica mudanças no seu modo de vida, nas suas relações objetivas e subjetivas. Contudo, para que tais mudanças sejam efetivadas são necessárias condições concretas para o seu desenvolvimento, com vistas à emancipação política ${ }^{2}$ das famílias e à efetivação dos seus direitos sociais, atrelada à adesão dos sujeitos - condição elementar à sua realização.

Considerando que os profissionais que atuam no âmbito da política de assistência social atendem a uma população que majoritariamente é alijada de informações sobre seus direitos, cabe a eles serem agentes de democratização dessas informações. Em face disso,

\footnotetext{
${ }^{2}$ Em Marx, a emancipação política é considerada uma etapa da emancipação humana. Segundo o autor, a emancipação humana (a vida livre, digna e feliz) só se processará com a ruptura da propriedade privada e com a constituição de uma sociedade comunista. Por isso, a emancipação política dos sujeitos não é uma emancipação de fato, existe um limite nessa concepção, visto que as bases estruturais do sistema capitalista precisam ser rompidas, através de uma revolução impulsionada pelos trabalhadores.
} 
podem contribuir para desocultar processos subalternizantes e instigar processos emancipatórios.

Pensar em propostas nessa dimensão implica pensar em ações que tragam mudanças na realidade concreta das famílias. Destacando-se que, para o trabalho socioeducativo ter impacto, é essencial que seja construído a partir do seu cotidiano de vida e de suas necessidades, de forma democrática e participativa. "Por isso, o estabelecimento de vínculos e a conformação de uma relação democrática entre profissional e usuários são fundamentais para que o processo alcance seus objetivos" (MIOTO, 2009, p. 504).

Destaca-se ainda, conforme explana Abreu (2002), que o trabalho socioeducativo, envolve a concepção da educação popular, proposta por Paulo Freire. Enquanto instrumento político na perspectiva da educação emancipatória volta-se para a formação de sujeitos capazes de participar crítica e conscientemente das práxis transformadora; elementos indispensáveis aos processos de luta e de organização da classe trabalhadora.

Portanto, o trabalho socioeducativo, na perspectiva aqui adotada, é entendido como uma ferramenta político-pedagógica, de forma que, a partir dela, os sujeitos possam ampliar seus processos de consciência, refletir sobre sua condição e seu lugar na sociedade de classes. Na compreensão marxista, vê-se o processo de consciência

(...) como um desenvolvimento dialético, em que cada momento traz em si os elementos de sua superação, em que as formas já incluem contradições que, ao amadurecerem, remetem à consciência para novas formas e contradições, de maneira que o movimento se expressa num processo que contém saltos e recuos (IASI, 2007, p. 12).

Desse modo, a conscientização não pode deixar de existir fora da prática refletida, pois a "práxis humana é a unidade indissolúvel entre a ação e a reflexão sobre o mundo" (FREIRE, 1979, p. 15). Somente a práxis, enquanto ação prático-crítica, pode modificar de modo substancial o produto materializado como intervenção profissional, mesmo considerando seus limites na sociabilidade em curso.

Portanto, não basta desvelar a realidade para que haja conscientização, é necessário transformar essa realidade pela ação prática sobre ela. Em outras palavras, os homens e mulheres tornam-se sujeitos políticos quando tomam consciência de sua ação transformadora frente ao mundo.

Nessa direção, o trabalho socioeducativo supõe compromisso com o processo societário das classes subalternas e competência teórico-metodológica, ético-política e técnico-operativa para a identificação e apropriação das reais possibilidades postas pelo movimento do real. 
Outro elemento importante no trabalho socioeducativo refere-se à busca pelo protagonismo das famílias para que elas conquistem espaços na sociedade e se reconheçam como ser político. Algumas literaturas, em especial as de Costa (2004), sugerem espaçosmomentos específicos para o desenvolvimento do trabalho socioeducativo, como atividades grupais. Nessas atividades, o participante é "identificado como um dos protagonistas do processo interativo e não como um receptor dos serviços estabelecidos previamente pelo poder público ou mesmo pelas organizações” (TORRES, 2009, p. 18).

Portanto, no trabalho em grupo os participantes podem articular forças vivas de resistência, de crescimento e de libertação, além de construírem vínculos e trocarem experiências, sem perder de vista as singularidades dos integrantes.

No entanto, pensar o potencial do trabalho socioeducativo como promotor de mudanças não significa atribuir a esse recurso o poder de restaurar aquilo que foi histórica e socialmente "tirado" dos indivíduos, pois estes continuam inseridos em contextos desiguais e opressores.

A esse respeito, Campos (2004) reitera o desafio do trabalho com famílias, pois elas estão envolvidas num complexo de relações, as quais ultrapassam os vínculos entre os indivíduos que compõem as famílias, abrangendo outras esferas. Isso significa que o trabalho socioeducativo vai além da simples concepção de mudança a partir do indivíduo, devendo considerar as estruturas em que está inserido. Logo, as famílias "não são ilhas nem tampouco meros intermediários entre o indivíduo e a sociedade. São a própria sociedade, uma vez que estão atravessados por ela e a constituem (ANDALÓ, 2006, p. 34).

Desse modo, é necessário considerar, no percurso do trabalho socioeducativo, a realidade das famílias em sua totalidade, para não correrem o risco de naturalização, culpabilização e criminalização de suas condições de vida, de seus modos de pensar e de agir. Nesse sentido, suas demandas devem ser interpretadas como expressão de necessidades humanas não satisfeitas, decorrentes das desigualdades próprias do capitalismo.

Igualmente é importante identificar nesse processo as mediações ${ }^{3}$, que envolvem o cotidiano de vida das famílias atendidas pela política de assistência social, pois é a categoria mediação que permite analisar os fenômenos sociais para além da sua imediaticidade, funcionando como um conduto através do qual se processam as relações entre as várias instâncias do real.

3 Categoria que permite o movimento entre o universal-particular-singular para compreensão crítica do todo. 
Salienta-se que, no decorrer do trabalho socioeducativo, o profissional vale-se, além dos conteúdos teóricos, de instrumentos e de técnicas para operacionalizar o seu fazer, proporcionando às famílias momentos de reflexão crítica sobre a realidade e possibilitando a transformação, ainda que processual, de seus processos de consciência.

Por isso, o trabalho socioeducativo requer discutir com as famílias assuntos que venham ao encontro de sua realidade, propiciando-lhe experimentar o sentido de pertencimento ao grupo, o que pode ser objetivado por meio de dinâmicas, vivências, debates, palestras e/ou oficinas. Isso é fundamental "porque as pessoas estão cada vez mais perdendo sua identidade e seus laços de pertencimento e o sentimento de valor próprio enquanto pessoa" (OLIVEIRA, 2011, p. 253).

Dessa forma, reconhecer as condições objetivas de vida das famílias é ponto primário para o desenvolvimento do trabalho socioeducativo. Ademais, esse conhecimento deve direcionar o planejamento do trabalho, visto as particularidades que envolvem os contextos familiares.

Entender o trabalho socioeducativo como um recurso metodológico para instigar a reflexão e a ação política é pensar em intervenções que considerem o homem não só como produto e produtor da sua história pessoal, mas também da história da sociedade. Do contrário, estar-se-á "reproduzindo as condições necessárias para impedir a emergência das contradições e a transformação social" (LANE, 2004a, p. 15).

Nesse contexto, lembra Prates (2007, p. 232), é preciso valer-se de todas as estratégias que possam aguçar a nossa sensibilidade e a criticidade para desvendar a realidade e nela intervir, "o que pressupõe o necessário reconhecimento de que, sem articulação entre razão e sensibilidade, não avançamos em processos que se queiram transformadores”. Essas são ideias fundamentais para a compreensão do trabalho socioeducativo e para pensá-lo como proposta interventiva dos profissionais que atuam no âmbito da política de assistência social. .

\section{Considerações finais}

Buscou-se, neste artigo, ampliar o debate sobre o trabalho socioeducativo com as famílias no âmbito da política de assistência social. Considerou-se a identificação de novas abordagens propostas pelo SUAS as quais possibilitam desenvolver ações na perspectiva da autonomia das famílias, tendo como horizonte a reafirmação da assistência social como política pública de direito. 
Nesse sentido, é necessária a superação de práticas assistencialistas e paternalistas, o que requer, por um lado, a compreensão das políticas sociais no Brasil, do papel Estado e das organizações capitalistas e, por outro, a apropriação de um referencial teórico crítico que proporcione uma visão global da dinâmica societária.

Há que se ter claro que no Brasil as políticas sociais apresentam profundos paradoxos, pois, embora garantidas constitucionalmente, sofrem sérios impedimentos ao seu reconhecimento como direitos conquistados, em virtude de regulações à ordem “capitalista internacional, com seu caráter regressivo e conservador, que focaliza, ameaça o direito e a cidadania, trazendo de volta a meritocracia, a disciplinarização, a refilantropização, a criminalização da Questão Social” (RAICHELIS, 2013, p. 619).

Ao se pensar no trabalho socioeducativo com famílias, é essencial uma intervenção profissional menos improvisada e teoricamente legitimada, a qual se baseie em procedimentos teórico-metodológicos, ético-políticos e técnico-operativos, de forma que o pensamento e a ação sejam coerentes e proporcionem concretude aos princípios e diretrizes que os norteiam.

Em face disso, o trabalho socioeducativo, dependendo da direção assumida, poderá contribuir para o fortalecimento das famílias atendidas no âmbito da política de assistência social, a fim de levá-las a uma participação ativa na vida em sociedade.

Com base nesses pressupostos, percebe-se a importância de se analisar o significado do trabalho socioeducativo no âmbito do SUAS. Para tanto, exigem-se ações profissionais fincadas na realidade das famílias que, para além de "consertá-las", ofereçam suporte para enfrentarem suas vidas, incidindo em seu cotidiano e contribuindo para que se reconheçam como sujeitos da sua própria história.

\title{
REFLECTIONS ON THE EDUCATIONAL WORK IN THE CONTEXT OF THE SINGLE SYSTEM OF SOCIAL ASSISTANCE
}

\begin{abstract}
This article discusses the importance of educational work with families on social assistance policy and the implications of this work in the everyday life of the subjects involved, especially when it comes to their ways of thinking and acting. It is understood that the innovations brought by the Social Assistance System (Your) point as methodological referential to the intervention of professionals. Accordingly, we seek to clarify the educational work as one of the paths to instigate emancipative processes along families and realize that involve Their principles, acknowledging the advances and the limits of this process.
\end{abstract}

Keywords: Educational work. Social assistance policy. Social Service. 


\section{REFLEXIONES SOBRE EL TRABAJO PEDAGÓGICO EN EL CONTEXTO DEL SISTEMA ÚNICO DE ASISTENCIA SOCIAL}

\section{Resumen}

Este artículo discute la importancia del trabajo educativo con las familias sobre la política de asistencia social y las implicaciones de este trabajo en la vida cotidiana de los sujetos involucrados, especialmente cuando se trata de sus formas de pensar y actuar. Se entiende que las innovaciones trajeron por el sistema de Asistencia Social (su) punto metodológico referencial a la intervención de profesionales. Por consiguiente, tratamos de aclarar el trabajo educativo como uno de los caminos a instigar procesos emancipative junto con las familias y darse cuenta de que involucran a sus principios, reconociendo los avances y los límites de este proceso.

Palabras clave: Trabajo educativo. Política de asistencia social. Servicio Social.

\section{Referências}

ABREU. Marina Maciel. Serviço Social e a organização da cultura: perfis pedagógicos da prática profissional. São Paulo: Cortez, 2002.

ANDALÓ, Carmen. Mediação grupal: uma leitura histórico-cultural. São Paulo: Ágora, 2006.

BARBOSA, Juliana Alves. O trabalho socioeducativo no sistema único de assistência social: reflexões sobre o pensar e o agir dos trabalhadores sociais. 2013. 176 f. Dissertação (Mestrado em Desenvolvimento Humano: Formação, Políticas e Práticas Sociais) Universidade de Taubaté, Taubaté. 2013.

BRASIL. Ministério do Desenvolvimento Social e Combate à Fome. Política Nacional de Assistência Social - PNAS/2004.. Brasília, 2004. Disponível em: <http://www.sesc.com.br/mesabrasil/doc/Pol\%C3\%ADtica-Nacional.pdf>. Acesso em: 15 nov. 2015.

\footnotetext{
Ministério do Desenvolvimento Social e Combate à Fome. Orientações técnicas sobre o PAIF - Volume 2. Brasília, 2012. Disponível em: <http://www.mds.gov.br/webarquivos/publicacao/assistencia_social/Cadernos/Orientacoes_P AIF_2.pdf >. Acesso em: 15 nov. 2015.
}

CAMPOS, Marta Silva . Fortalecendo Famílias. In: WANDERLEY, M.B. (Org). Trabalho com famílias: textos de apoio. v.2, São Paulo: IEE-PUC, 2004.

COSTA, Antonio Carlos Gomes da. As bases éticas da ação sócio-educativa: referenciais normativos e princípios norteadores. Brasília: 2004.

FREIRE, Paulo. Educação e Mudança. 12 ed. Rio de Janeiro: Paz e Terra, 1979.

IASI, Mauro Luis. Ensaios sobre consciência e emancipação. São Paulo: Expressão Popular, 2007. 
LANE, Silvia Tatiana Maurer. Psicologia social e uma nova concepção do homem para psicologia. In:___; CODO, Wanderley. (Org). Psicologia Social: O homem em movimento. São Paulo: Brasiliense, 1995.

LIMA, Evangelina Sanches; CARLOTO, Cassia Maria. Ações socioeducativas: reflexões a partir de Freire. Emancipação, Ponta Grossa/PR, v.9 n.1, p.127-139, 2009.

LÖWY, Michael. Ideologias e ciência Social: elementos para uma análise marxista. 16.ed. São Paulo: Cortez, 2003.

MARX. Karl. Crítica da filosofia do direito de Hegel. São Paulo: Boitempo, 2005.

MARX, Karl; ENGELS, Friedrich. Manifesto do Partido Comunista. São Paulo: Cortez, 1989.

MIOTO, Regina Celia Tamaso. Família e serviço social: contribuição para o debate. Revista Serviço Social e Sociedade. São Paulo: Cortez, n.55, p.115-130, 1997.

. Cuidados sociais dirigidos à família e segmentos sociais vulneráveis. In: CONSELHO FEDERAL DE SERVIÇO SOCIAL. O trabalho do assistente social e as políticas sociais, mod. 04, Brasília, UnB, CEAD, 2000.

A centralidade da família na Política de Assistência Social: contribuições para o debate. In: Revista de Política Pública. São Luis: EDUFMA, v. 8, n. 1, jan. / jun. 2004.

Orientação e acompanhamento a indivíduos, grupos e famílias. Curso de Especialização Serviço Social: Direitos Sociais e Competências Profissionais. Brasília: CFESS/ABEPSS, 2009. p. 497-512.

OLIVEIRA, Hilda Côrrea . Assistência Social, mobilização e educação popular. In: CONSELHO FEDERAL DE SERVIÇO SOCIAL. O trabalho do/a assistente Social no SUAS: seminário nacional. Brasília - DF: CFESS, 2011.

PRATES, Jane Cruz. A arte como matéria-prima e instrumento de trabalho para o assistente social. Revista Virtual Textos \& Contextos, Porto Alegre, v. 6, p.221-232, jul./dez. 2007.

RAICHELLIS. Raquel. Proteção social e trabalho do assistente social tendências e disputas na conjuntura de crise mundial. Revista Serviço Social \& Sociedade, São Paulo, n. 116, p. 609635, out./dez. 2013

SPOSATI, Aldaíza. Contribuição para a construção do Sistema Único de Assistência Social SUAS. In: Revista Serviço Social e Sociedade, nº 78, ano XXIV. São Paulo: Cortez, 2004.

TORRES, Mabel Mascarenhas. As múltiplas dimensões presentes no exercício profissional do assistente social: intervenção e o trabalho sócio-educativo. Serviço Social em revista, Londrina, 2009.2 Disponível em:<www.uel.br/revistas/uel/index.php//ssrevistas/article/view/10060/8789. Acesso em 16 de novembro de 2015. 
YAZBEK, Maria Carmelita. O Serviço Social e o movimento histórico da Sociedade brasileira. In: Conselho Regional de Serviço Social São Paulo (Org.). Legislação brasileira para o Serviço Social: coletânea de leis, decretos e regulamentos para instrumentalização do (a) assistente social. 2. ed. São Paulo:Conselho Regional de Serviço Social, 2006. p. 13-29.

. Estado e Políticas Sociais. Política Social e Serviço Social: elementos históricos e debate atual. Revista Praia Vermelha. Rio de Janeiro: UFRJ, v.18, n.1, 2008.

Data de recebimento: 07/04/2016

Data de aceite: 13/06/2017

\section{Sobre as autoras:}

Lindamar Alves Faermann é Assistente Social, graduada em Serviço Social pela Universidade de Taubaté/SP. Mestre e doutora em Serviço Social pela Pontifícia Universidade Católica de São Paulo. Professora da graduação e da pós-graduação na Universidade de Taubaté. Atualmente coordena o Curso de Serviço Social da UNITAU e o Projeto de Extensão Assessoria aos profissionais da educação do município de Taubaté. Pesquisadora do Núcleo de Estudos Serviço Social, Trabalho e Políticas Sociais, com produções na área de fundamentos do Serviço Social, trabalho, instrumentalidade e política educacional. Endereço Eletrônico: lindafaermann@yahoo.com.br

Dannúbia Aparecida Nascimento é Assistente Social. Trabalha na Prefeitura Municipal de Lagoinha-SP. Especialista em Serviço Social na Área Judiciária pela Pontifícia Universidade Católica de São Paulo. Especialista em Políticas Sociais e Trabalho Social com Famílias pela Universidade de Taubaté. 